Nakil, S.

Research Paper

\title{
Traditional and Modern Systems for AddressingWater Scarcity in Arid zones of India
}

\author{
Ar. Seemantini NAKIL, Associate Professor \\ DY Patil School of Architecture Ambi, Pune India
}

\begin{abstract}
Water is essential for all socio-economic development and for maintaining a healthy ecosystem in the world. At present, reduction of water scarcity is prime goal of many countries and governments. Water scarcity is one of the most important concerns of present-day geographers as water is the central subject of all kinds of developmental activities. Rajasthan is the largest state in India covering an area of 34.22 million hectares, i.e.10.5 percent of the country's geographical area, but sharing only 1.15 percent of its water resources. The state is predominantly agrarian as the livelihood of 70 percent of its people depends on agriculturebased activities. Most of the state (60-75\%) is arid or semiarid. Waterways are a vital and productive resource to our environment. Rajasthan in India is characterized by very low mean annual rainfall (100-400 mm), high inter-annual variability in rainfall and stream flows, and poorquality soils and groundwater. Rajasthan has a rich history of use of traditional systems of water harvesting in almost all the districts of the state. These practices have often saved the droughtaffected regions from problems of water famine. The serious problems of water shortages in many parts of the country are being largely attributed to the discontinued use of traditional water harvesting practices. This paper discusses reasons of scarcity of water in arid zones and also explore various traditional \& modern water systems to resolve the issue of water scarcity in arid parts of India.
\end{abstract}

\section{Keywords}

Water Scarcity, Rajasthan, reasons, Scarcity. address, traditional \& modern systems

\section{Introduction}

Water is the most important natural resource and is vital for all life on earth. The well-being and the development of our society are dependent on the availability of water. This most precious resource is sometimes scarce sometimes abundant and is always very unevenly distributed, both in space and times (Reddy, 2011). Water is needed to ensure food security, feed livestock, and take up industrial production and to conserve the environment. Water scarcity involves water stress, water shortage or deficits, and water crisis. This may be due to both nature and humans. Water has been harvested in India since antiquity, with our ancestors perfecting the art of water management. Traditionally Many water harvesting structures and water conveyance systems specific to the eco-regions and culture has been developed. They harvested the rain drop directly. From rooftops, they collected water and stored it in tanks built in their courtyards. From open community lands, they collected the rain and stored it in artificial wells. They harvested monsoon runoff by capturing water from swollen streams during the monsoon season and stored it various forms of water bodies. They harvested water from flooded rivers. 
Nakil, S.

\section{Arid Zones of India}

The Indian desert occupies over 3.2 lakh square kilometres of hot desert located in Rajasthan, Haryana and Gujarat. besides small pockets in peninsular India. An area of about 70,000 sq. kilometres of cold desert in Ladakh JD Jammu and Kashmir, presents desertic conditions entirely different from the hot desert. The area under the desert in India is about three and a-half times the combined area of the States of Punjab and Haryana. About 20 million persons live in the Indian desert. The problem of desert control becomes quite complex and challenging because the technology evolved has to be introduced and implemented effectively in a manner that it not only sustains but improves large human and cattle population. Besides its economic and social importance, the desert has direct and indirect influences on the entire country. Agricultural production and living standards in the rural areas located in the more favourable conditions of the country are increasing and have caused regional disparities and imbalances.

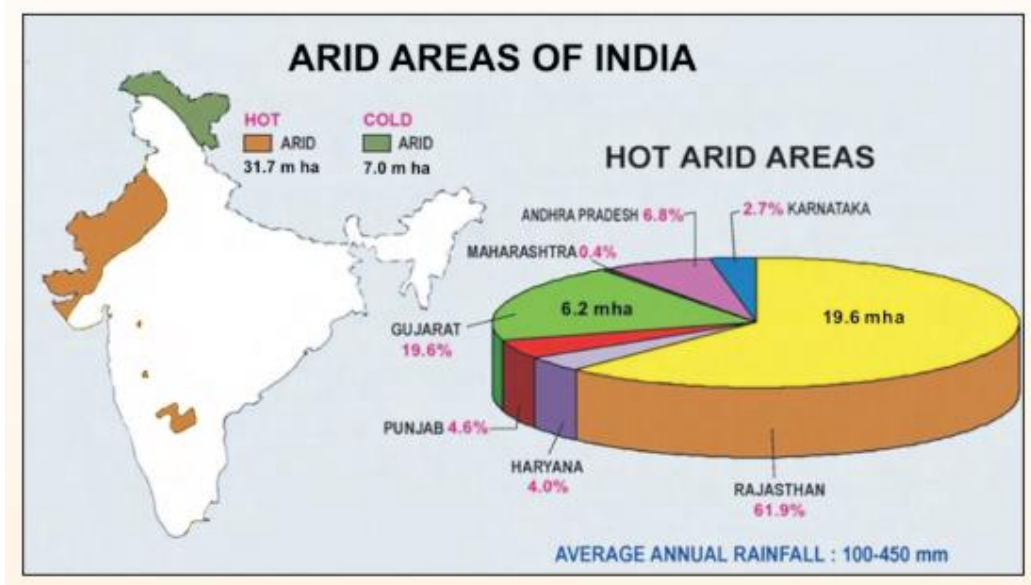

Figure 1 Arid Zones of India(Source: CAZRI report)

\subsection{Aridity Explained}

In view of strong monsoon circulation peculiar to Indian subcontinent, the weather conditions during monsoon in the Indian arid. zone are different from those of other deserts. Though actual rainfall is low the humidity of air is high and is almost similar to- other places with higher rainfall in semi- arid and sub. humid zones.

\subsection{Impact of Climate Change}

Low and erratic rainfall coupled with extreme temperatures and intense solar radiation makes these regions the most vulnerable regions in India. Arid regions are expected to undergo significant climate changes, but there is considerable variability and uncertainty in these estimates between different scenarios. The complexities of precipitation changes, vegetation-climate feedbacks and direct physiological effects of $\mathrm{CO} 2$ on vegetation present particular challenges for climate change modeling of arid regions.

According to Mr. R.K.Pachauri from IPCC, the potential for drier conditions in arid and semi-arid regions is very high, leading to severe water shortages and leave the incomes of the vulnerable populations much lower and increase the absolute number of people at risk of hunger. He also emphasized the vulnerability of certain regions that will be double exposed to dangers of climate change and globalization. 
Nakil, S.

\subsubsection{Expected precipitation changes}

A trend of increasing monsoon seasonal rainfall has been found along the west coast, northern Andhra Pradesh and north western India ( $+10 \%$ to $+12 \%$ of the normal over the 100 years) while a trend of decreasing monsoon seasonal rainfall has been observed over eastern Madhya Pradesh, north-eastern India, and some parts of Gujarat and Kerala ( $-6 \%$ to $-8 \%$ of the normal the 100 years).

Concentration of droughts is projected in Gujarat and Rajasthan, which are already drought-prone, and in Orissa, which is currently flood-prone.

\subsection{Water sources in the arid and semi-arid regions}

Water is scarce in these regions. The groundwater tables and rainfall are low, and the water run-off is high. Annual rainfall is between 100 and $400 \mathrm{~mm}$ or 400 and $800 \mathrm{~mm}$. The water resources of the arid region are scarce and because of low and erratic rainfall, replenishment is also very poor. The quantity and quality of water available from various sources such as surface water and ground water is not adequate even for drinking purposes. Apart from insufficient quantity, the ground water is moderate to highly saline over large area. A dominantly sandy terrain, the disorganized drainage network (drainage-1 density is as low as $0.3 \mathrm{~km}$ ) and high annual potential evapotranspiration (1400-2000-1 mm year ) leads to a permanent negative water balance (Rao, 2009). Recurring drought sand consequent crop failures are regular events in this zone.

The northern arid regions, comprising largely of the desert of Rajasthan, the Rann of Kutch and the semiarid regions of Punjab and Gujarat, are entirely dependent on groundwater and above-the-ground tanks, ponds, other traditional stores of water. No rivers flow through these regions. The Southern peninsula, however, is fed by the peninsular rivers, mainly fed through groundwater discharges and supplemented by monsoon rains.

The main source of water throughout the year for these regions is through small and medium stored water. In many areas, the tank is the only water source to store rainwater.

\section{Study Area}

\subsection{Rajasthan}

Rajasthan is the largest state in India covering an area of 34.22 million hectares, i.e., 10.5 percent of the country's geographical area, but sharing only 1.15 percent of its water resources. The state is predominantly agrarian as the livelihood of 70 percent of its people depends on agriculture-based activities. Most of the state (60-75\%) is arid or semiarid. In the last 50 years, a threefold increase in the human population and a doubling of the livestock populations have put tremendous pressure on the fragile water and land resources of Rajasthan. Recurring and prolonged droughts, particularly in the western arid part of the state, is a common phenomenon exacerbating water shortage. The estimated annual, per capita water availability in the state during 2001 was $840 \mathrm{~m} 3$ and it is expected to be $439 \mathrm{m3}$ by the year 2050, against the national average of $1,140 \mathrm{~m} 3$ by 2050 . Groundwater is overexploited in many districts of the state.

During the last 50 years, the human population has increased threefold and currently stands at 58.20 million. The cultivated area is $20,798,311$ hectares with a cropping intensity of 124 percent, which leads to an increasing demand for water in the same or in a higher proportion. All this call for an exploration of the potential for water harvesting, its conservation and efficient utilization to withstand growing demand, especially during droughts. The objective of this study was to assess 
the traditional and innovative water harvesting and conservation technologies in the context of their potential for drought mitigation throughout the state of Rajasthan.

\section{Methodology and Approach}

Study is based on the exploratory research method, through literature study various commonly used traditional water harvesting systems are taken as a part of study. The first part of the paper tried to understand arid zones of India and issues arid parts of India are facing through literature study. The methods of traditional water harvesting systems chosen as a part of study, as they are still alive and people are still using these traditional harvesting systems to overcome scarcity of water. Further literature study contribute to explain modern ways of water harvesting system in arid zones of Indian context especially in Rajastan which is considered as one of the shortest rain fall zone.

\section{Water Harvesting and its potential for Drought Mitigation}

Water harvesting and conservation at basin, area, field or micro level can bring sustainability to the water sector and, consequently, increase water availability in drought years. Water harvesting is the process of concentrating rainfall as runoff from a catchment to be used in a target area.In Rajasthan, and particularly in the low-rainfall western zone, there are several kinds of rainwater harvesting systems such as bawari, jhalara, talab, nadi, tanka, khadin, kund and harvesting of roof water. Out of these, bawari and jhalara depend on groundwater, while talab, nadi, tanka, kund and khadin are based on harnessing surface runoff (Khan 1995; Khan and Narain 2000). With the implementation of government schemes for domestic water supply in many areas, some of these systems were neglected. However, with increasing human population, shortfall in groundwater and recurring droughts, these rainwater harvesting systems are attracting growing attention. Modern technologies of rainwater harvesting and groundwater recharge such as anicut, percolation tank, subsurface barrier and pond with infiltration wells have recently been developed to rejuvenate the depleted freshwater aquifers (Khan 1996a; Khan 1996b; Narain and Khan 2000;Narain and Khan 2002).

\subsection{Traditional water harvesting systems}

\subsubsection{Bawari and Jhalara}

Bawari and jhalara are local names given to step wells. These ancient water harvesting systems were mainly set up in cities and big towns to provide a water supply to the community. They were constructed at exorbitant cost and were often monumental, beautiful mansions with fine embroidery stone works covering large areas and were associated with religion and culture.
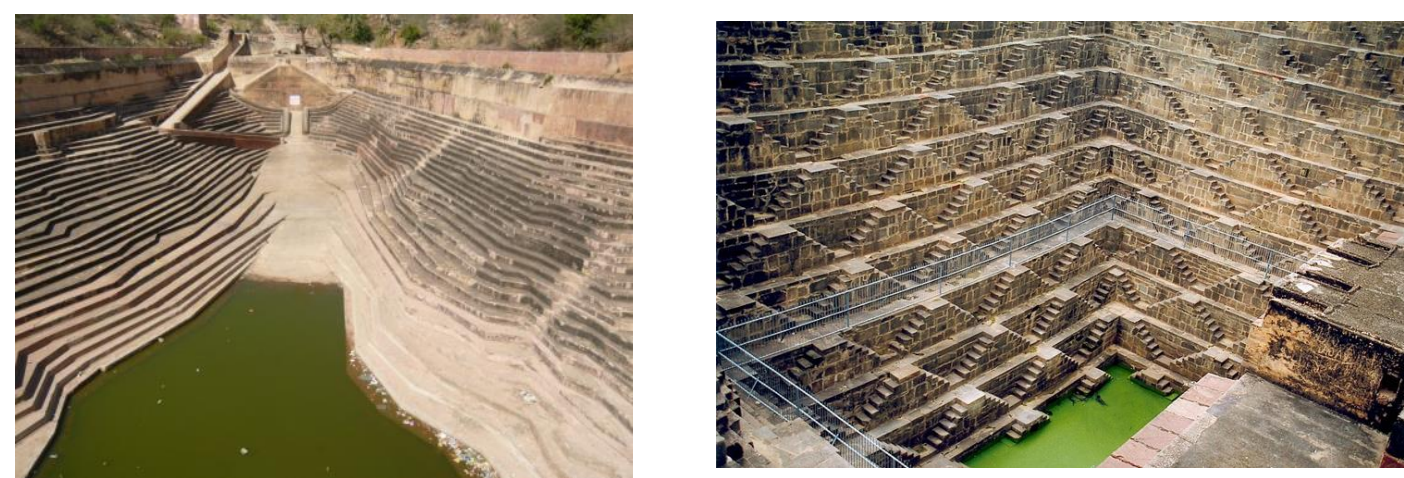

Figure 2:Jhalara \& Bawari,traditional water harvesting sysem(Source-wikipedia) 
Stepwells are basically deep dug trenches or rock-cut wells or ponds of water reached by a winding set of stairs or steps and are variously known as 'bawdi', 'baoli', 'vav', 'vavdi', 'vai', 'kalyani', or 'pushkarni'. it always had to collect the water of the monsoon rains and keep it accessible for the remaining dry months of the year. Stepwells were accessible by stair steps. A small room under the surface was used as spring-basin or draw-basin. The water was collected in the middle of the basin and people transported the water into bowls, jars or with pipes to the surface. These step-wells were $12 \mathrm{~m}$ deep, $2 \mathrm{~m}$ high and $4 \mathrm{~m}$ wide (Kramer 2002). With this system water could be grained even in very deep aquifers.

\subsubsection{Paar system:}

Paar is a common water harvesting practice in the western Rajasthan region. It is a common place where the rainwater flows from the agar (catchment) and in the process percolates into the sandy soil. In order to access the rajani pani (percolated water) kuis or beris are dug in the agor (storage area). Kuis or beris are normally 5 metres $(\mathrm{m})$ to $12 \mathrm{~m}$ deep. The structure was constructed through traditional masonary technology. Normally six to ten of them are constructed in a paar. However depending on the size of the paar the numbers of kuis or beris are decided. Bhatti mentions that there are paars in Jaisalmer district where there are more than 20 kuis are in operation. This is the most predominant form of rainwater harvesting in the region. Rainwater harvested through PAAR technique is known as Patali paani.
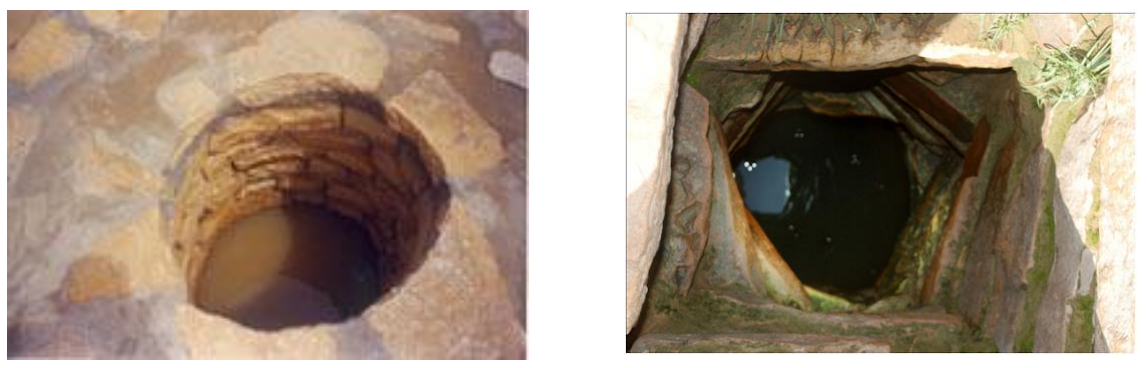

Figure 3:paar system of Rain water collection (Source:cse webnet)

\subsubsection{Rapat System}

A rapat is a percolation tank, with a bund to impound rainwater flowing through a watershed and a waste weir to dispose of the surplus flow. If the height of the structure is small, the bund may be built of masonary, otherwise earth is used. Rajasthan rapats, being small, are all masonry structures. Rapats and percolation tanks do not directly irrigate land, but recharges well within a distance of 3-5 $\mathrm{km}$ downstream. Silting is a serious problem with small rapats and the estimated life of a rapat varies from 5 to 20 years.

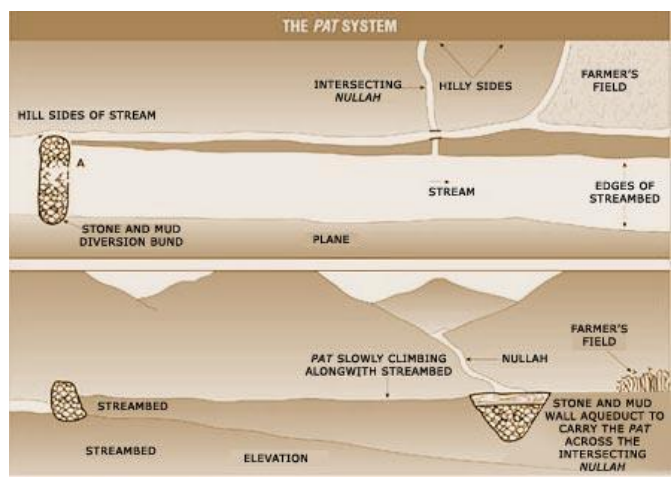

Figure 4:Section of PAT system (Source:CRIDA)

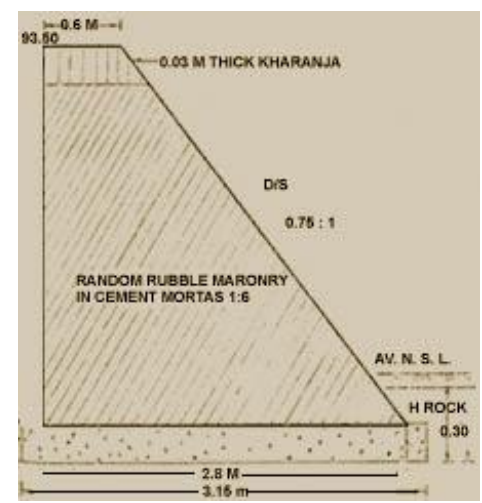

56 ${ }^{\text {th }}$ ISOCARP World Planning Congress in Doha, Qatar International Society of City and Regional Planners 
Nakil, S.

\subsubsection{Khadin}

A Khadin, also called a Dhora, is an ingenious construction designed to harvest surface runoff water for agriculture. Its main feature is a very long $(100-300 \mathrm{~m})$ earthen embankment built across the lower hill slopes lying below gravelly uplands. Sluices and spillways allow excess water to drain off.

uring monsoon rain significant run off is generated in the gravelly uplands of the catchment. The catchment area is generally 15 times the area of the Khadin. This water is held back by the bund and saturates the soil in the Khadin area. Excess water is released from by a sluice or spillway and then crops are grown in the moist soil. Salinity is often a problem in dry land irrigation however this system avoids it due to the intermittent flushing of salts from the Khadin area. Below the bund shallow groundwater levels are raised and shallow wells are installed for drinking water. First designed by the Paliwal Brahmins of Jaisalmer, western Rajasthan in the 15th century, this system has great similarity with the irrigation methods of the people of Ur (present Iraq) around $4500 \mathrm{BC}$ and later of the Nabateans in the Middle East. A similar system is also reported to have been practiced 4,000 years ago in the Negev desert, and in southwestern Colorado 500 years ago.
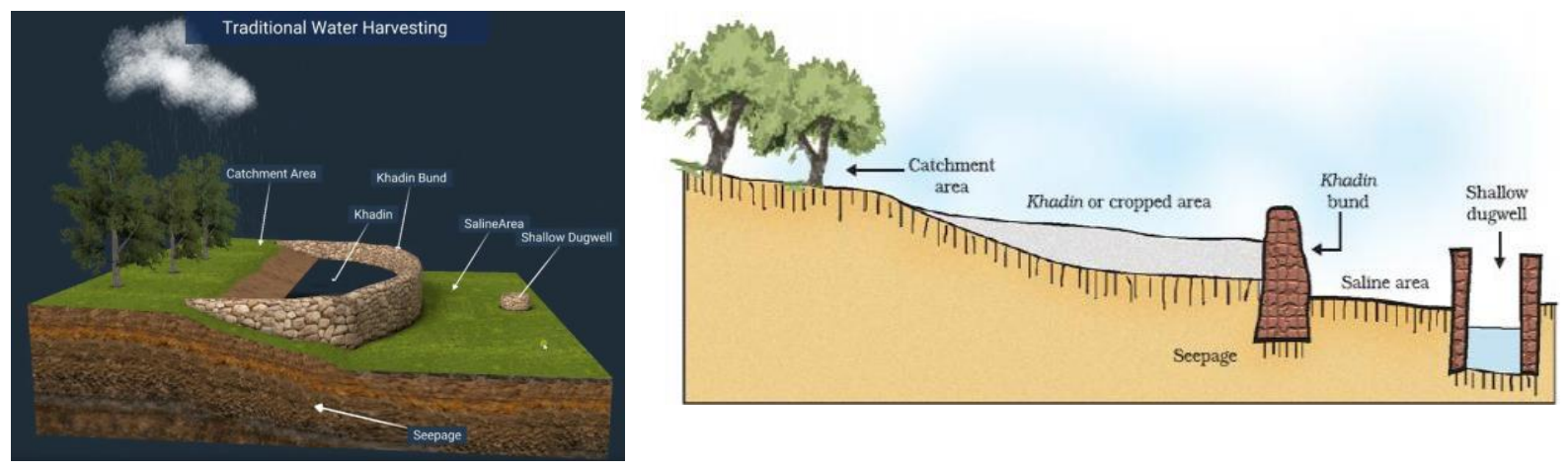

Figure 5:Section of Khadim water harvestion system(sourse:CSE webnet)

\section{Modern methods of Water System}

The Central Arid Zone Research Institute, Jodhpur was established in 1959 to combat desertification and evolve sustainable land management technologies. Over five decades of research the Institute has evolved watershed management technologies of soil and water conservation for the management and sustainable development of the arid lans

\subsection{Watershed Management}

The term 'watershed' implies to an area which has well defined hydrological as well as geographical boundaries from where the entire runoff drains towards a single outlet. A watershed captures precipitation, filters and stores water and determines its release. A watershed also includes groundwater aquifers that discharge to and receive discharge from other streams. Watershed management is defined as "Rational utilization of land and water resources for optimum and sustained production with minimum hazard to natural resources. It essentially relates to soil and water conservation in the watershed which means proper land use, protecting land against all forms of deterioration, buildingand maintaining soil fertility, conserving water for farm use, proper management of water for drainage, flood protection, sediment reduction and increasing productivity from all land uses." Watershed management programs can be developed to provide monetary benefits as well as positive environmental/ecological and social/cultural impacts. Upland development, if carried out using sound watershed management principles, can offer an array of economic benefits to both upland watershed inhabitants and down-stream 
Nakil, $\mathrm{S}$.

\subsection{Anicut/Check-dams}

Check-dams are masonry overflow barriers (weirs) constructed across seasonal streams (Fig-7). A check-dam as such has a relatively limited storage capacity but a largebvolume of water can still be pumped from such storage as the stream continues to flow and the check-dam serves the purpose of an ideal intake structure. A check-dam, by storing the base flow, maintains a supply of water for recharge as well as for direct use beyond the monsoon period (Goyal and Narain, 2006). It creates flooding of upstream area, which requires surplusing arrangements at suitable intervals to drain water. Checkdam should be avoided in isolation. The number of check-dams primarily depends upon the slope of the gully and the quantity of runoff. It may not be advisable to construct check-dams on bigger streams with high gradient and where runoff is very high. The bigger streams should be treated with drainage line treatment like gabionic structures and boulder checks with masonry work to curtail the runoff.
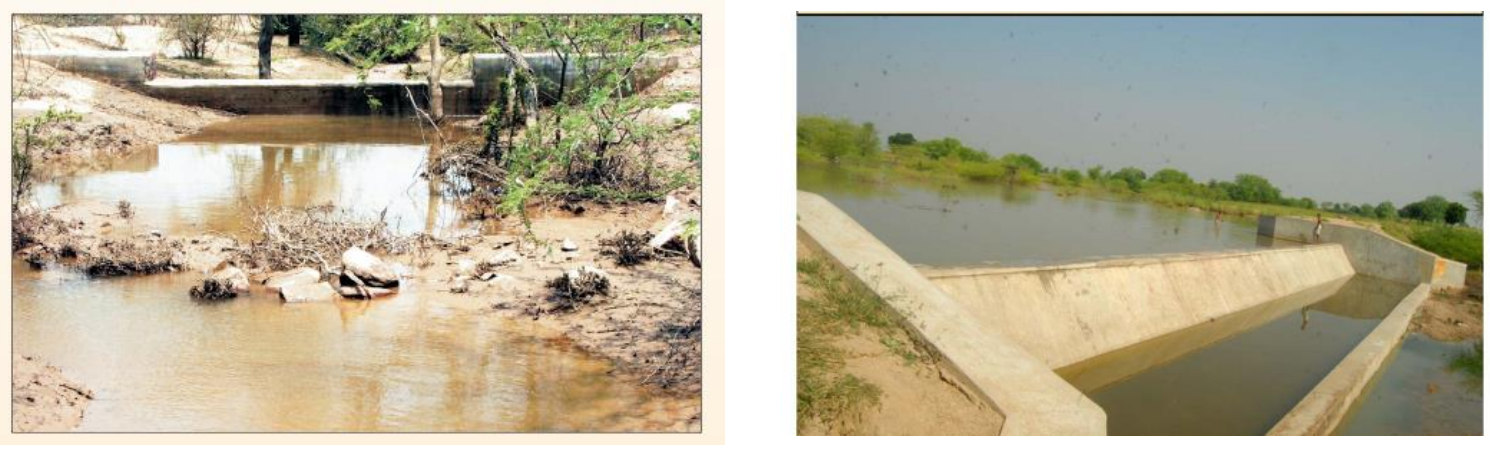

Figure 6:Checkdams (Source :Wikipedia)

\subsection{Rain water Harvesting Through Tanks}

Tankas (small tanks) are underground tanks, found traditionally in most part of western Rajasthan. They are generally built in the main house or in the courtyard. Tanka is a circular hole made in the ground, lined with fine polished lime for collection of rainwater primarily from rooftop of individual house. The water collected in small tankas is generally used for drinking purposes, however bigger tanka can be used for providing supplemental/lifesaving irrigation to horticultural plants. During subnormal rainfall when tanka does not get adequate rainwater, water is hauled in camel/bullock cart from nearby wells/nadis to fill the household tankas. For rainwater management, CAZRI has designed 33 underground tanka of $10 \mathrm{~m}$ to $600 \mathrm{~m}$ capacities for different rainfall and catchment conditions. These tankas were successfully constructed in Jhanwar, Sar, Baorali-Bambore (Jodhpur district) and Kalyanpur (Barmer district) villages. Harvested water of these tankas was used to provide life saving irrigation to plants. The Benefit cost ratio of tanka ranged from 1.25 to 1.40 under different uses (Goyal et al., 1995, 1997; Goyal and Sharma, 2000). The improved design of tanka has provision for inlet and outlet with silttrap for control of silt inflow with runoff (Fig-9). The catchment of a tanka is made by spreading the excavated material around the structure.

\subsection{Birkha Bawri at Jodhpur in Rajasthan}

The Umaid Heritage Site is a private township located in southeast of the Umaid Bhawan Palace in Jodhpur, Rajasthan and was faced with acute water shortage. To overcome this problem, a Rain Water Harvesting (RWH) system was developed inside the housing complex. The Birkha Bawri as the 
Nakil, $\mathbf{S}$.

structure draws inspiration from traditional step wells in the region and is used to catch rainwater from the site catchment area. Apart from storage and conservation of rainwater, the project also highlights sustainable storm water management in the housing complex, as it collects runoff and minimizes water logging in the area. The rainwater is collected from open areas through natural slopes as well as from the roof top of the house connected through drainage conduits. The water enters from both sides of the underground longitudinal storage structure (Bawri) and holds 17.5 million liters of harvested rainwater annually and serves as a reliable source of water for meeting landscape requirements. The steep depth of the tank (18 meters) provides shade to water and reduces evaporation losses. The water stored in the structure is used to supply water to the residents during lean periods and also to meet horticulture needs.

\section{Outcome}

The RWH system has greatly reduced dependence on municipal water supply and groundwater extraction by $50 \%$. Economic benefits such as reduction in use of water tankers have led to savings of Rs. 2.36 crore annually. The structure has increased property value of the complex by demonstrating perfect combination of good architectural design and well maintained green spaces in scanty rainfall region. Overall dependence on municipal storm water structure has lessened and water logging controlled. The project provides green landscaped area to the site, which is hugely sustainable. (Source : SELECTED BEST PRACTICES IN WATER MANAGEMENT by Niti Aayog August 2017, with support of TERI university)

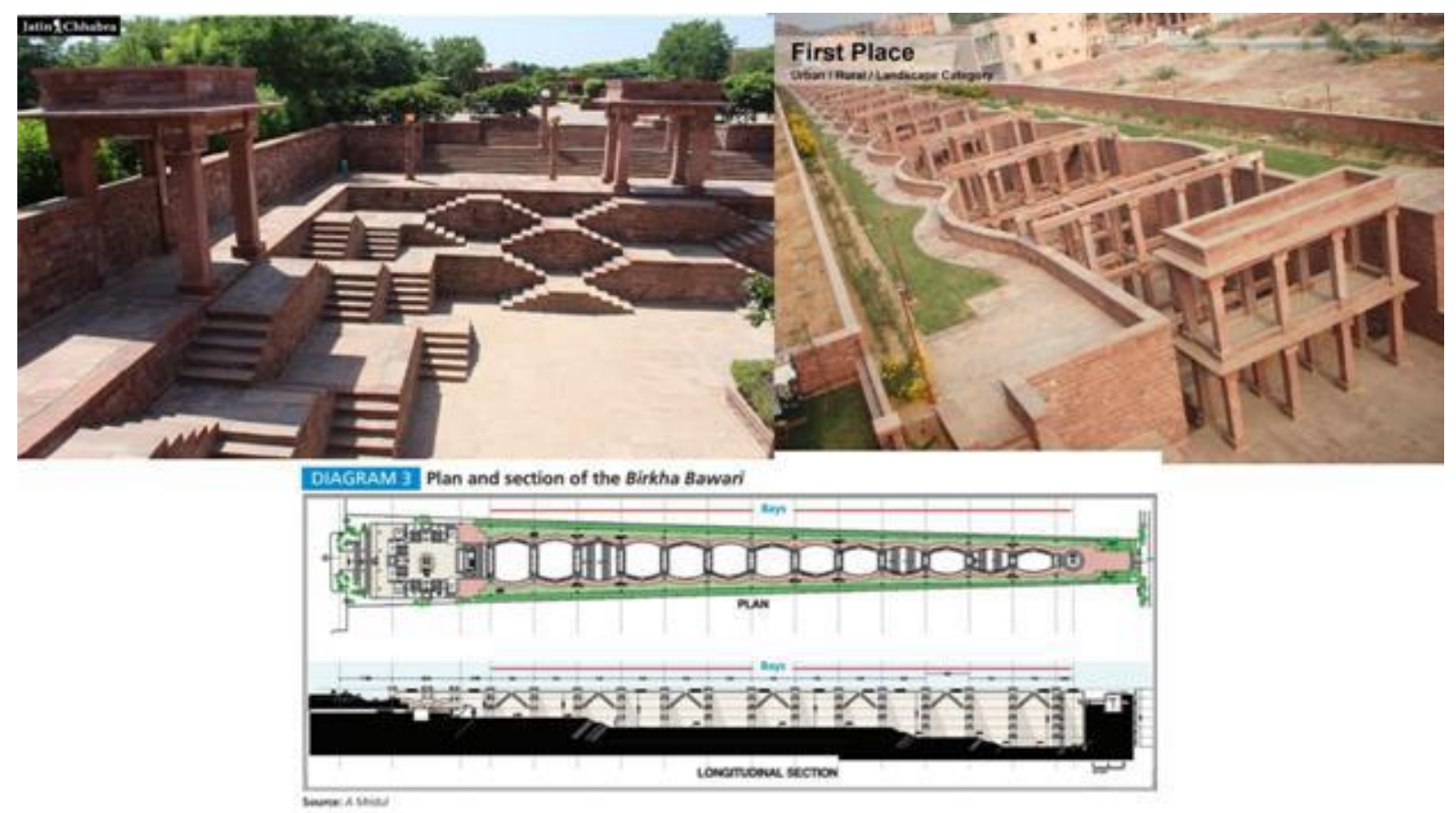

Figure 6:Modern water harvesting system based on the traditional system(Source:NGO initiatives) 


\section{Conclusion}

Worldwide arid zones have witnessed increase in human and livestock populations like any other region as a result of natural increase. The traditional systems of water harvesting, like the bawari, jhalara, nadi, tanka, khadin, etc., prevalent in the region over centuries, are still viable and costeffective. If these systems are improved and utilized on a large scale, they can meet the requirements of drinking water of the rural population and mitigate the drought impact at least partially. In addition, modern rainwater technologies, such as anicuts, percolation tanks, injection wells and subsurface barriers, are highly effective in rejuvenating depleted groundwater aquifers. With the existing and proposed rainwater harvesting structures in the arid zones of Rajastan, over 68 MCM of water will be available even during severe droughts, which may suffice to meet nearly 69 percent of the requirements of drinking water in arid zones.

\section{References}

AFPRO (1994) Survey conducted by AFPRO (Agriculture for Food Production) in Village Buja, Alwar District, Rajasthan. Ecologist Asia, 11(3), July-September 2003.

Basic Statistics of Rajasthan (2003) Directorate of Economics and Statistics, Government of Rajasthan. Jaipur, India.

Central Groundwater Authority (CGWA) (1999) Groundwater situation status of development and proposed strategy and policy for management in Rajasthan. Jaipur, India: CGWA. Page no. 22.

Central Groundwater Board (CGWB) (2011) Select case studies rain harvesting and artificial recharge, page no 9-11. Central Groundwater Board, Ministry of Water Resources, New Delhi.

Das, S. (2010) Johads of Alwar. Journal of Geological Society India 75(2), 446-447.

Geological Survey of India (2011) Geology and mineral resources of Rajasthan, Miscellaneous Publication, No. 30 Part $12 \bullet$ 3rd Revised Edition, page 1-2, Govt. of India.

Frontline (2001) The Water Man of Rajasthan, Volume, 18, Issue, 17, August 18-23 .

Husain, I. and Husain, J. (2012) Traditional \& Successful Practices in Water Scarcity "Thar Desert", Rajasthan, India. World Water Week 2012, SIWI, Stockholm.

Kavarana, G. (2006) The value of a raindrop. Traditional RWH systems, particularly in the arid and semiarid regions of Rajasthan and Gujarat. UNESCO G-WADI meeting on water harvesting Aleppo Syria 20-22, November, 2006, p. 54.

Khan, M. A. and Narain, P. (2000) Traditional water harvesting systems and their relevance in the present context. In: National Seminar on Groundwater Management Strategies in Arid and Semi Arid Regions. Proceedings. Jaipur, India: Groundwater Department, Government of Rajasthan, pp. 19-27Mitchell.

Basic Statistics of Rajasthan 2003. Directorate of Economics and Statistics, Government of Rajasthan. Jaipur,

India.

Vision-2025 for Rajasthan. 2004a. Central Ground Water Board, Western Region. Jaipur, India.

Vision-2045. 2004b. Irrigation Department, Government of Rajasthan. Jaipur, India.

X-th Five-year Plan. 2004c. Government of Rajasthan, Jaipur, India.

CGWA (Central Ground Water Authority). 1999. Ground water situation status of development and proposed 


\section{Nakil, S.}

strategy and policy for management in Rajasthan. Jaipur, India: CGWA. 22 pp.

Khan, M. A. 1995. Traditional water management systems of western Rajasthan. In. 2nd Congress on Traditional Science and Technology of India. Proceedings. Madras, India: Anna University. 220 pp.

Khan, M. A. 1996a. Sustainable development of water resources to augment rural water supply and to improve

biomass production in arid ecosystem of Rajasthan. In III Water Congress, Indian Institute of Technology. Proceedings. New Delhi, India. 136 pp.

Khan, M. A. 1996b. Inducement of groundwater recharge for sustainable development. In 28th Annual Convention, Indian Water Works Association, Jodhpur, India. Pp.147-150. 